\title{
DISTRIBUTION OF ABO AND RHESUS (D) BLOOD GROUP AMONG MBBS STUDENTS IN A TERTIARY CARE TEACHING MEDICAL COLLEGE \& HOSPITAL IN KANCHIPURAM, INDIA
}

\author{
Anand Ashok Bhosale1, Sithy Athiya Munavarah², Nainar Jeybalan ${ }^{3}$ \\ 1 Professor, Department of Pathology, Karpaga Vinayaga Institute of Medical Sciences, Kanchipuram, Tamilnadu, India. \\ ${ }^{2}$ Professor and HOD, Department of Pathology, Karpaga Vinayaga Institute of Medical Sciences, Kanchipuram, Tamilnadu, India. \\ 3Professor, Department of Pathology, Karpaga Vinayaga Institute of Medical Sciences, Kanchipuram, Tamilnadu, India.
}

\section{ABSTRACT}

\section{BACKGROUND}

Several blood group systems have been identified but ABO and Rhesus blood groups are the most important in transfusion medicine. The $\mathrm{ABO}$ and Rhesus (Rh) blood group systems are important for transfusion of blood and its components, organ transplantation, genetic studies and in medico-legal issues. Despite the long list of several other blood groups discovered so far, the knowledge and distribution of ABO and Rh-D blood group is essential for effective management of blood bank inventory.

\section{MATERIALS AND METHODS}

This study presents data about the prevalence of $\mathrm{ABO}$ \& Rhesus (Rh) blood groups amongst 103 second year medical students. The study was conducted at Blood Bank of Karpaga Vinayaga Institute of Medical Sciences \& in association with department of pathology, in Kanchipuram (India).

\section{RESULTS}

Blood group B was found to be commonest among the study population with prevalence of $47(45.63 \%)$, followed by 0 , A and AB in that order. Most of the students were found to be Rhesus positive while only a minority were Rhesus negative. This finding will be useful in health care planning, genetic counselling and running of an organized, efficient and safe blood transfusion services.

\section{CONCLUSION}

It can be concluded that B blood group is more common than other blood groups among $\mathrm{ABO}$ system and $\mathrm{AB}$ being the least common. Rhesus positive blood groups were found to be more common than Rhesus negative.

\section{KEY WORDS}

Rh Factor, ABO Blood Group, Agglutination Method.

HOW TO CITE THIS ARTICLE: Bhosale AA, Munavarah SA, Jeybalan N. Distribution of ABO and rhesus (D) blood group among MBBS students in a tertiary care teaching medical college \& hospital in Kanchipuram, India. J. Evolution Med. Dent. Sci. 2019;8(06): 355-358, DOI: $10.14260 /$ jemds/2019/78

\section{BACKGROUND}

India is a vast country with great diversity in race, religion, and creed. The same diversity has been observed in geographical distribution of blood groups in population within country. Blood provides an ideal opportunity for the study of human variation without cultural prejudice. It can be easily classified for many different genetically inherited blood typing systems. Also significant is the fact that we rarely take blood types into consideration in selecting mates.

International Society of Blood Transfusion has recently recognized 33 blood group systems. Apart from ABO and Rhesus system, many other types of antigens have been noticed on the red cell membranes. Blood grouping and cross-matching is one of the few important tests that the anaesthesiologist orders during preoperative period. Hence, a proper understanding of the blood group system, their clinical significance, typing and cross matching tests, and

'Financial or Other Competing Interest': None.

Submission 07-01-2019, Peer Review 02-02-2019,

Acceptance 04-02-2019, Published 11-02-2019.

Corresponding Author:

Dr. Anand Ashok Bhosale,

Department of Pathology,

Karpaga Vinayaga Institute of Medical Sciences,

GST, Road, Chinnakolambakkam,

Kanchipuram-603308, Tamilnadu, India.

E-mail: anandbhosale2007@gmail.com

DOI: $10.14260 /$ jemds $/ 2019 / 78$

\section{(c) $($ ) $\$$}

current perspective are of paramount importance to prevent transfusion-related complications. Nonetheless, the knowledge on blood group system is necessary to approach blood group-linked diseases, which are still at the stage of research. ${ }^{1}$

People have different blood types, known as blood groups. Antigens are hereditary determined and plays a vital role in transfusion safety. The discovery of the ABO blood groups by Karl Landsteiner was an important achievement in the history of blood transfusion followed by discovery of $\mathrm{Rh}$ antigen. ${ }^{2}$

The success of human blood transfusions requires compatibility for the two major blood group antigen systems, namely $\mathrm{ABO}$ and $\mathrm{Rh}$. The ABO system is defined by two red blood cell antigens, $A$ and $B$, whose presence or absence is determined by three alleles (A, B, O) segregating (be separated at meiosis) at a single genetic locus. An unusual feature of this system is the presence of serum IgM antibodies in healthy adults to whichever antigen (A or B) is absent from that individual's cells. The presence or absence of $\mathrm{Rh}$ antigens on red blood cells is determined by two alleles at another locus, Rh. ${ }^{3}$

There are differences in the distribution of $\mathrm{ABO}$, and $\mathrm{Rh}$ (D) blood groups amongst different populations. The study of blood groups plays an important role in various genetic studies, in clinical studies for reliable geographical information and in blood transfusion practice, which will help in reducing morbidity and mortality rate. Knowledge of 
distribution of $\mathrm{ABO}$ and Rhesus (Rh) blood group is also essential for effective management of blood bank inventory. ${ }^{4}$

The regulation of $\mathrm{ABO}$ blood group system is under the control of $\mathrm{ABO}$ gene expression. These genes located on the long arm of the autosomal locus at chromosome number 9 , which constitute the four blood types. The gene symbols $A, B$, $\mathrm{AB}$ and $\mathrm{O}$ are often used to denote these alleles. Two alleles, $\mathrm{R}$ and $r$, are responsible for the inheritance of rhesus blood groups, with $\mathrm{R}$ denoting $\mathrm{Rh}$ positive, and $\mathrm{r}$ being $\mathrm{Rh}$ negative allele. Gene frequency takes into consideration the numbers of various genotypes in the population, and the relative allele frequencies are determined by application of the HardyWeinberg Law. In the coming years, 0 was found more suitable in defining blood and the blood groups were named as $\mathrm{A}, \mathrm{B}, \mathrm{O}, \mathrm{AB} .{ }^{5}$

For the effective management of blood banks and safe blood transfusion services, understanding ABO blood group types and Rhesus (Rh) factor distribution at local and regional levels is very essential. This study perhaps documents for the first time, $\mathrm{ABO}$ and Rhesus blood group distribution in rural tertiary hospital. It will serve to provide information that is useful in emergency situations where donors are required.

Blood bank usually has a problem of ever-changing stock position and it being very difficult to predict the prevalence of a particular blood group at a particular time.

Many lives are saved throughout the world each year through the use of blood and blood components transfusions, by preventing death from loss of blood due to trauma, and by allowing performance of surgical procedures which would otherwise be impossible. However, it was not possible until the early nineteen hundreds that routine blood transfusion between humans. Now it became possible, following the discovery that genetically determined differences exist between the bloods of different individuals. These differences must be identified, and compatibility ensured before transfusions can be safely carried out.

A wide range of studies have been conducted to determine the frequency of $\mathrm{ABO}$ and Rhesus blood groups with diverging phenotypic results across various populations in different geographical regions

Distribution of Blood group knowledge is also important in reducing maternal mortality rate because of access to safe and sufficient blood supply. This helps in reducing many preventable deaths. This Blood group knowledge is also important for clinical studies and geographical information. Blood group system in modern medicine, is important because of the relation between different blood groups with different diseases and environment. Hence, it is important to know about the pattern of blood group distribution in any population. Therefore, this present study was conducted to know the $\mathrm{ABO}$ and $\mathrm{Rh}$ blood group distribution among medical students in Kanchipuram.

\section{MATERIALS AND METHODS}

This observational study was conducted on second year medical students who volunteered to take part in the study, in the Department of Pathology at Karpaga Vinayaga Institute of Medical Sciences, Kanchipuram. The Institutional ethical committee clearance was obtained.

Blood Group was done by test tube agglutination method. Both forward (Cell grouping) \& reverse grouping (Serum grouping) method were done. Final blood group was confirmed only if both forward \& reverse groups are identical. The donor blood group data were recorded on specially formed pro forma.

\section{Statistical Analysis}

The data was analysed, and final results were listed according to frequency and gender. Data was expressed in percentages.

\section{RESULTS}

One hundred three results were obtained, made up of 45 males and 58 females. The age of the students ranged between $18-23$ years with mean age of 20 years. Among the population studied, blood group B had the highest frequency, 47 (45.63\%), followed by blood group 0, 26 (25.24\%), then A $23(22.33 \%)$, while $\mathrm{AB}$ had the least frequency, $07(6.79 \%)$ (Table 1).

According to the rhesus system, most of the students were found to be Rhesus positive with frequency of 95 (92. 23\%) while Rhesus negative was 08 (7.76\%) (Table 1).

Among the male students, blood group B Rh positive was the highest with a frequency of $20(44.44 \%)$, followed by blood group $0 \mathrm{Rh}$ positive with a frequency of $10(22.22 \%)$, Frequency of blood group $\mathrm{A} \mathrm{Rh}$ positive and $\mathrm{O} \mathrm{Rh}$ negative were $8(17.7 \%)$ and $3(6,66 \%)$ respectively. Likewise, among the female students, blood group 'B' Rh Positive had the highest frequency, 25 (43.10\%), followed by blood group 0 $\mathrm{Rh}$ positive with a frequency of $13(22.41 \%)$, then blood group A Rh positive, 12 (20.68\%) while blood group B Rh negative was the least, 1 (1.72\%) (Table $1 \& 2$ ).

With respect to rhesus blood group system among the population studied, blood group $\mathrm{B}+$ was the most common with frequency of $45(43.68 \%)$, followed by $0+$ with frequency of $23(22.33 \%)$, then $A+20(19.41 \%)$ and $A B+, 7$ $(6.79 \%)$ whereas among the rhesus negative students, blood group 0 - and A- were the most frequent 3 (2.91\%) each, and B- was $2(1.94 \%)$ while blood group AB- was 0 , as shown in Table 2 .

\begin{tabular}{|c|c|c|c|}
\hline Blood Group & Rh Positive & Rh Negative & Total \\
\hline A & 20 & 3 & $23(22.33 \%)$ \\
\hline B & 45 & 2 & $47(45.63 \%)$ \\
\hline AB & 7 & 0 & $7(6.79 \%)$ \\
\hline O & 23 & 3 & $26(25.24 \%)$ \\
\hline Total & $95(92.23 \%)$ & $8(7.76 \%)$ & $103(100 \%)$ \\
\hline Table 1. ABO \& Rh Blood Group Distribution Amongst \\
Medical Students \\
\hline
\end{tabular}

\begin{tabular}{|c|c|c|c|}
\hline Blood Group & Male & Female & Total \\
\hline 'A' Rh Positive & $8(17.7 \%)$ & $12(20,68 \%)$ & $20(19.41 \%)$ \\
\hline 'B' Rh Positive & $20(44.44 \%)$ & $25(43.10 \%)$ & $45(43.68 \%)$ \\
\hline 'AB' Rh Positive & $2(4.44 \%)$ & $5(8.62 \%)$ & $7(6.79 \%)$ \\
\hline 'O' Rh Positive & $10(22.22)$ & $13(22.41 \%)$ & $23(22.33 \%)$ \\
\hline 'A' Rh Negative & $1(2.22 \%)$ & $2(3.44 \%)$ & $3(2.91 \%)$ \\
\hline 'B' Rh Negative & $1(2.22 \%)$ & $1(1.72 \%)$ & $2(1.94 \%)$ \\
\hline 'AB' Rh Negative & 0 & 0 & 0 \\
\hline 'O' Rh Negative & $3(6.66 \%)$ & 0 & $3(2.91 \%)$ \\
\hline Total & $45(100 \%)$ & $58(100 \%)$ & $103(100 \%)$ \\
\hline
\end{tabular}




\section{DISCUSSION}

$\mathrm{ABO}$ and $\mathrm{Rh}$ blood group distribution studies are important as they play a major role in blood transfusion, transplantation of organs, research in the field of genetics, human evolution and forensic pathology. Some blood groups are more prone for some diseases like diabetes mellitus, duodenal ulcers, UTI.(6)

During the First World War in 1919, the blood group investigation started in this subcontinent with Hirschfled determining blood groups among large number of soldiers including India and found that B blood group was more frequent. Blood groups are known to have genetic association with some diseases. Studies conducted shows that A group individuals are more prone for cardiovascular diseases like coronary heart disease, venous thrombosis, ischemic heart disease and atherosclerosis. These cardiovascular diseases are less likely in people with 0 blood group, which stated to have protective effect against these. These 0 group individuals are known to have protection against squamous and basal cell carcinoma with risk being reduced by $14 \%$ and $4 \%$ respectively as compared to other groups. It is also known to have less risk of pancreatic cancer. The ovarian cancer is more in individuals having B antigen. A group people have reported more association with gastric cancer whereas it is least in 0 group individuals. Therefore, it is important to do blood grouping studies in each and every region so as to draft appropriate national transfusion policies and to supply blood during emergency situations to the needy people.(7)

The ABO blood group system is one of the most clinically significant blood group systems because of the regular occurrence of antigen and antibodies of the blood group system and ability of antibodies of the system to cause haemolytic transfusion reaction and HDFN (Haemolytic Disease of the Fetus and Newborn). The prevalence of ABO blood groups varies from race to race.

Various blood group systems have been discovered in humans and extensively studied throughout the world. The spectrum of differences in human population may be attributed to genetic drift, migration, allele selection and random effects.

The blood group polymorphism has been extensively used to appreciate the similarities and differences among population. Blood transfusion remains a major therapeutic intervention encompassing all the clinical specialties of modern medicine. Transfusion of ABO incompatible blood leads to number of deaths since $A$ and $B$ antigens are the most immunogenic and the corresponding antibodies are often strongly haemolytic both in vivo and in vitro. Therefore, determination of blood groups is very crucial in blood transfusion. ${ }^{8}$

In this present study, we observed that $45(43.68 \%)$ of donors were blood group B Rh positive, 23 (22.33\%) were blood group $0 \mathrm{Rh}$ positive, 20 (19.41\%) were group A Rh positive, $7(6.79 \%)$ were group $\mathrm{AB}$ Rh positive, $3(2.91 \%)$ were blood group A Rh negative \& $\mathrm{O} R \mathrm{Rh}$ negative each, 2 (1.94\%) were group B Rh negative, with No donor was found of group $\mathrm{AB}$ Rh negative. Gene frequencies with respect to the $A B O$ system for the present study has shown a general formula $\mathrm{B}>\mathrm{O}>\mathrm{A}>\mathrm{AB}$ indicating a preponderance of allele $\mathrm{B}$ over allele $\mathrm{A}$.
Khan et al, showed the frequency of blood group B to be the highest among the Pakistan population studied. ${ }^{9}$

Study done in Latur ${ }^{10}$ described ' $B$ ' as the most frequent and ' $\mathrm{AB}$ ' as the least common blood group. ' $\mathrm{O}$ ' blood group was second most common, similar to findings in our study. Also, in rhesus system, 92. 23\% donors were Rh-positive, and $7.76 \%$ donors were $\mathrm{Rh}$ negative.

The studies by Hemalatha N.R. et.al. at Mandya, ${ }^{6}$ Chandra et al at Lucknow ${ }^{11}$ and Sindhu et al ${ }^{12}$ Punjab in Northern parts of India showed blood group $B$ was the commonest, followed by $\mathrm{O}, \mathrm{A}$ and $\mathrm{AB}$, which is similar to this study. B blood group was also found to be predominant $(36.5 \%)$ in Ahmedabad region, the western part of India followed by 0 (30.5\%), A (21\%) and AB (12\%). ${ }^{13}$ Studies done at Surat by Nidhi Mehta et al14 and Giri h15 et al in Maharashtra, showed that the B group was commonest among people studied followed by $\mathrm{O}, \mathrm{A}$ and $\mathrm{AB}$ groups, similar to present study. All these studies showed Rh positive as predominant group compared to Rh negative.

The understanding of prevalence of blood groups is important not only for transfusion medicine but also for organ transplant and genetic research purposes, human evolution, forensic pathology and some groups have shown associations with diseases like duodenal ulcer, diabetes mellitus, urinary tract infection and $\mathrm{Rh}$ and $\mathrm{ABO}$ incompatibilities of new born. The frequency of blood groups is variable amongst population in different parts of the world. Many studies have been conducted in different areas of India depicting the prevalent blood groups in that particular area.

Blood group distribution knowledge is not only important for management of blood bank but also for clinical departmental studies, geographical data analysis and forensic studies.

Blood groups are required for transfusion purposes, to prevent diseases associated with blood groups as well as to prevent dangerous transfusion reactions which occurs because of mismatched blood transfusions, effective management of blood bank and to provide blood to the emergency \& needy patients. This blood group distribution knowledge is important to determine recruitment of voluntary donors in case of emergencies. The importance of blood group determination lies in the transfusion of blood among different populations irrespective of their age, gender, ethnic origin, in organ transplantation and in the development of legal medicine, genetic research, and anthropology.

India carries a lot of diversity in the distribution of blood groups. Knowledge of frequency of blood groups is essential in determining the direction of recruitment of voluntary donors as required for different zones of the country. We compared our results with other studies carried out in different geographical areas.

\section{CONCLUSION}

Blood group B was found to be commonest among the study population with prevalence of 47 (45.63\%), followed by $0, \mathrm{~A}$ and $\mathrm{AB}$ in that order. Most of the students were found to be Rhesus positive while only a minority were Rhesus negative. This finding will be useful in health care planning, genetic counselling and running of an organized, efficient and safe blood transfusion services. Routine screening of blood group 0 for haemolysin is recommended to prevent haemolytic 
transfusion reaction. Rhesus negative blood was found to be rare. Institution of blood donor registry is also recommended for easy accessibility to rhesus negative blood for transfusion especially in cases of emergency and also to prevent haemolytic disease of the foetus and new born.

\section{ACKNOWLEDGEMENT}

The authors are thankful to Technical Staff of Blood Bank, all Teaching Staff of Department of Pathology and Managing Director for constant support in completing this work.

\section{REFERENCES}

[1] Mitra R, Mishra N, Rath GP. Blood groups systems. Indian Journal of Anaesthesia 2014;58(5):524-8.

[2] Rao CA, Shetty J. Frequency of ABO and Rhesus (D) blood groups in Dakshina Kannada district of Karnataka - a study from rural tertiary care teaching hospital in south India. Nitte University Journal of Health Science 2014;4(3):57-60.

[3] Khalid M, Aslam N, Siyar M, et al. Distribution of Abo and $\mathrm{Rh}$ (D) blood groups among blood donors in District Mardan, Pakistan. Journal of Saidu Medical College 2013;3(2):318-22.

[4] Eweidah MH, Rahiman S, Ali H, et al. Distribution of ABO and Rhesus (RHD) blood groups in Al-Jouf province of the Saudi Arabia. The Anthropologist 2011;13(2):99-102.

[5] Ghasemi N, Ayatollahi J, Zadehrahmani M, et al. Frequency of $\mathrm{ABO}$ and $\mathrm{Rh}$ blood groups in middle school students of Yazd province. Iranian Journal of Pediatric Hematology and Oncology 2007;1(1):27-30.
[6] Hemalatha NR. ABO and Rh blood group distribution among medical students in Mandya. International Journal of Contemporary Medical Research 2017;4(8):1655-8.

[7] Swamy CM, Basavaraj PB, Kavitha GU, et al. Prevalence of $\mathrm{ABO}$ and Rhesus blood group among blood donors. Indian J Public Health Res Dev 2012;3:106-9.

[8] Islam F, Robert H. Frequency of ABO and Rhesus blood groups in the population of Gilgit area of Pakistan. Pak Journal of Pathology 2010;21(3):87-91.

[9] Khan MI, Micheal S, Akhtar F, et al. Association of ABO blood groups with glaucoma in the Pakistani population. Can J Ophthalmol 2009;44(5):582-6.

[10] Deshpande RH. Distribution of blood groups in blood donors in blood banks of Latur. Sch J App Med Sci 2013;1:276-9.

[11] Chandra T, Gupta A. Frequency of ABO and Rhesus blood groups in blood donors. Asian J Trans Sci 2012;6(1):52-3.

[12] Sindhu S. Distribution of the ABO blood groups and Rh (D) factor among the scheduled caste population of Punjab. The Anthropologist 2003;5(3):203-4.

[13] Mod HS, Solanki A. The distribution of ABO and Rh (D) blood groups in local residents of Ahmedabad. International Journal of Scientific Research 2013;2(9):275-6.

[14] Mehta N, Swadas B. Prevalence of ABO blood groups at Mahavir Heart Institute Surat. Asian J Trans Sci 2012;6(1):74-5.

[15] Giri PA, Yadav S, Parhar GS, et al. Frequency of ABO and Rhesus blood groups: a study from a rural tertiary care teaching hospital in India. Int J Biol Med Res 2011;2(4):988-90. 